\title{
The Combined Effect of Squid Pen Chitooligosaccharide and High Voltage Cold Atmospheric Plasma on the Quality of Asian Sea Bass Slices Inoculated with Pseudomonas aeruginosa
}

\author{
Avtar Singh ${ }^{1, *}(\mathbb{D})$, Soottawat Benjakul $^{1}$, Oladipupo Odunayo Olatunde ${ }^{1}$, \\ Ahmet Faruk Yesilsu² ${ }^{2}$
}

${ }^{1}$ International Center of Excellence Seafood Science and Innovation, Faculty of Agro-Industry, Prince of Songkla University, Hat Yai, Songkhla, 90110, Thailand.

${ }^{2}$ Central Fisheries Research Institute, Trabzon, Turkey.

\section{Article History}

Received 19 August 2020

Accepted 23 November 2020

First Online 24 November 2020

\section{Corresponding Author}

Tel.: +6674286334

E-mail: avtar.s@psu.ac.th

\section{Keywords}

Asian sea bass

Chitooligosaccharide

Lipid oxidation

Protein oxidation

High voltage cold atmospheric plasma Pseudomonas

\begin{abstract}
The effects of chitooligosaccharide (COS) at different concentrations $(0.05,0.1$ and $0.2 \%, \mathrm{w} / \mathrm{w}$ ) without and with the application of high voltage cold atmospheric plasma (HVCAP) at different ratios of argon ( $\mathrm{Ar}$ ) and oxygen $\left(\mathrm{O}_{2}\right), 90 \% \mathrm{Ar} / 10 \% \mathrm{O}_{2}$ and $80 \% \mathrm{Ar} / 20 \% \mathrm{O}_{2}$ on the growth of Pseudomonas aeruginosa inoculated (6 log $\mathrm{CFU} / \mathrm{mL}$ ) on Asian sea bass slices were monitored for 0 and $24 \mathrm{~h}$ incubation at $4{ }^{\circ} \mathrm{C}$. Impact of COS on the changes in lipid and protein oxidation caused by HVCAP was also determined. All the HVCAP treated slices showed reduction in Pseudomonas count (PC) as compared to control (without any treatment) at both 0 and $24 \mathrm{~h}$ of incubation $(p<0.05)$. However, decrease in PC was enhanced when HVCAP treated slices were combined with COS, particularly with higher $\mathrm{O}_{2}$ ratio $(20 \%)$. COS inhibited lipid and protein oxidation of the slices treated with HVCAP as indicated by lower peroxide value, thiobarbituric acid reactive substances (TBARS) and total carbonyl content. For all treated slices, total volatile base nitrogen (TVB-N) was decreased at both incubation times, compared to the control. Micrograph analysis showed perforated, deformed and distorted cells of Pseudomonas after treatment alone or in combination. Therefore, COS could lower microbial load when combined with HVCAP and simultaneously could reduce the adverse impact of both protein and lipid oxidation, in slices treated with HVCAP.
\end{abstract}

\section{Introduction}

Fish and fishery products are not only nutritional but also play an important role in global trade for a number of countries. Asian sea bass (Lates calcarifer) is one of the highly consumed fishes in Southeast Asia (Arfat et al., 2015). The high water content (70-72\%) and fat (6.5-7\%) especially polyunsaturated fatty acids (PUFA) and protein (19-20\%) of Asian seabass made it more susceptible to microbial spoilage microorganisms and lipid oxidation (Sae-leaw \& Benjakul, 2017; Arfat et al., 2015). With increasing demand for seafoods, several innovative techniques such as modified atmospheric pressure, high pressure processing, pulsed electric field, ultrasound, and gamma irradiation, etc. for shelf-life extension, quality maintenance, and product safety have been introduced (Arfat et al., 2015). To achieve the current demands, novel natural additives and nonthermal processing have gained increasing attention due to lower losses in sensory and nutritional properties of finished products than thermal processing such as canning, pasteurization and sterilization (Arfat et al., 2015; DeWitt \& Oliveira, 2016). Cold atmospheric plasma (CAP) has been implemented since 1990s, however its use for preservation of food has been highlighted recently. Plasma is an ionized gas containing molecules or atoms with approximately zero net electrical charge in its metastable state (Singh \& 
Benjakul, 2020). High voltage has been used to ionize gas molecules to electrons, atomic ion species, free radicals, UV photon, and ozone (Smet et al., 2018) so called high voltage cold atmospheric plasma (HVCAP). Nonetheless, the exact microbial inhibition mechanism of HVCAP is not fully unraveled. HVCAP causing the rupture of cell and modification of microbial DNA, proteins, lipids, etc. via accumulated free radical and charged particles was proposed by Smet et al. (2018). Although those radicals or active species can induce the damage of microbial cells, they augment oxidation of lipids and proteins, causing the loss in nutrients and acceptability of foods (Singh \& Benjakul, 2020). Olatunde et al. (2019a) reported that gas composition, treatment time, and post-treatment time determined the antibacterial efficiency of HVCAP and quality of sea bass slices. Moreover, HVCAP produced with argon (Ar) has excellent antibacterial potential; however, argon alone was unable to produce ozone as the reactive species due to the absence of oxygen. Generally, ozone is produced from the interaction of a molecular diatomic oxygen with an oxygen atom (de Mendonça Silva \& Gonçalves, 2017). Therefore, inclusion of oxygen is necessary to obtain HVCAP with superior antimicrobial properties. Generally, ozone and other reactive species at high concentrations act as prooxidant which induce lipid oxidation in foods containing lipid (Gavahian et al., 2018). In our previous study, Asian sea bass slice treated with HVCAP caused higher oxidation of lipids and protein, resulting in development of off-flavor (Singh \& Benjakul, 2020). Therefore, the use of antioxidant in combination with HVCAP might help overcome the aforementioned limitations.

Various studies have been performed to use HVCAP as a shelf-life enhancing tool for various foods (Gavahian et al., 2018; Olatunde et al., 2019; Pankaj et al., 2017). Moreover, antibacterial impact of HVCAP on spoilage and pathogenic bacteria has been documented (Rothrock et al., 2017). On the other hand, scarce information is available regarding the use of HVCAP in food challenged with microbes, especially seafoods. Pseudomonas has been known to grow under the aerobic atmospheric condition in the refrigerated seafood and is the major contributor for spoilage in seafood (Gram \& Dalgaard, 2002). This microorganism could determine the efficacy of HVCAP to reduce the growth of challenged microbe (Spanu et al., 2014). Challenge study might therefore help to determine the inactivation rate of Pseudomonas in refrigerated readyto-eat Asian sea bass slices (ASBS) using the selected preservation method and additive.

Squid (Loligo formasana) pen, a source of $\beta$-chitin, is generally considered as waste by the squid processing industry (Singh et al., 2017; Singh et al., 2020). $\beta$-chitin shows higher reactivity towards various solvent $(\mathrm{NaOH}$, acetic acid, etc.) than $\alpha$-chitin due to its looser confirmation, therefore it can be easily deacetylated to chitosan followed by hydrolysis using non-specific enzymes to produce chitooligosaccharide (COS) (Lodhi et al., 2014; Singh et al., 2019b). COS has been used in various medicine and food due to its non-toxicity, numerous bioactivities and high solubility (Lodhi et al., 2014). COS is known to possess excellent antibacterial as well as antioxidant properties (Lodhi et al., 2014). However, less information has been available for the utilization of COS from squid pen as the natural additive in seafoods, particularly in ASBS.

The aim of the current study was to elucidate the individual and combined effects of COS and HVCAP under various conditions against $P$. aeruginosa inoculated on ASBS at time 0 and $24 \mathrm{~h}$ of incubation at 4 으. The impact of COS at various levels on lipid and protein oxidation of ASBS induced by HVCAP with the different working gases (argon and oxygen) was also investigated.

\section{Materials and Methods}

\section{Chemicals, Lipase, Bacterial Strain and Asian Sea Bass}

Analytical grade chemicals and lipase from porcine pancreas were acquired from Sigma-Aldrich, Inc. (St. Louis, MO, USA). Microbial media were obtained from Oxoid (Hampshire, England). P. aeruginosa PSU.SCB.16S.11 was gifted by the Food Safety Laboratory, Prince of Songkla University, Hat Yai, Thailand.

Freshly caught Asian sea bass (weight: $1.2-1.5 \mathrm{~kg}$, length: $42 \mathrm{~cm}$ ) were obtained from a local market of Hat Yai, Thailand. The fishes were brought to laboratory within $1 \mathrm{~h}$ under cool condition maintained by ice (ice/fish ratio of $3: 1, w / w)$. One batch containing two fishes were filleted using a sharp knife, which were further sliced into pieces having thickness of $1.5-1.8 \mathrm{~cm}$ with the weight of 10-12 g each. The moisture, protein, fat and ash contents were found to be $71.25 \pm 1.26$, $19.89 \pm 0.36,6.58 \pm 0.12$ and $1.84 \pm 0.02 \%$, respectively as determined by AOAC methods (AOAC, 2002). The $\mathrm{pH}$ of the fresh fish was around 6.6 60.5 .

\section{Preparation of Chitooligosaccharide (COS)}

Firstly, squid pen chitosan was extracted as per the procedure of Singh et al. (2019b). For COS preparation, chitosan ( $1 \mathrm{~g})$ was dissolved in $1 \%(\mathrm{v} / \mathrm{v})$ acetic acid to get a final concentration of $1 \%(\mathrm{w} / \mathrm{v})$. Final $\mathrm{pH}$ of prepared solution was adjusted to 5 using $6 \mathrm{M} \mathrm{NaOH}$. The hydrolysis was performed at 50 ㅇ $\mathrm{C}$ for $12 \mathrm{~h}$ followed by the termination of the reaction by heating at 95 으 for 10 min. The obtained hydrolysate was adjusted to $\mathrm{pH} 7$ using $6 \mathrm{M} \mathrm{NaOH}$ followed by vacuum filtration. The obtained filtrate was subsequently freeze-dried using a freeze-dryer (CoolSafe 55, ScanLaf A/S, Lynge, Denmark). The COS had the average molecular weight of $75 \mathrm{kDa}$, intrinsic viscosity of $0.40 \mathrm{dL} / \mathrm{g}$ as determined by the procedure of Singh et al. (2019a). 


\section{Microbial Strain and Sub-Culture}

Glycerol stock of $P$. aeruginosa culture preserved in a deep freezer $\left(-80^{\circ} \mathrm{C}\right)$ was revived and cell number was adjusted to $6.0 \log \mathrm{CFU} / \mathrm{mL}$ in $0.85 \%$ saline prepared in $0.1 \mathrm{M}$ phosphate buffer $(\mathrm{pH} 7.4)$ as per the method described by Singh et al. (2019a).

\section{Treatment of Slices with COS and Pseudomonas Inoculation}

The COS was dissolved in least amount of water ( 25 $\mathrm{mL}$ for $1 \mathrm{~kg}$ of slices). One kilogram (1 kg) of slices having the thickness of $1.5-1.8 \mathrm{~cm}$ was manually mixed thoroughly for $2 \mathrm{~min}$ with COS solution $(25 \mathrm{~mL})$ to obtain the final concentrations of $0.05,0.1$ and $0.2 \%$. COS treated slices were inoculated with Pseudomonas (2 $\mathrm{mL} / 100 \mathrm{~g}$ ) using a UV treated (15 $\mathrm{min}$ ) brush to obtain approximately $6.0 \mathrm{log} \mathrm{CFU} / \mathrm{g}$ slices. The treated samples were allowed to dry for $60 \mathrm{~min}$ under sterile conditions using Laminar air flow hood at 20 으 (Singh \& Benjakul, 2020). All the treated samples were divided into two batches. One batch was put into multilayer low-density polyethylene bags ( $30 \mathrm{~g}$ each) $\left(18 \times 28 \mathrm{~cm}^{2}\right)$. Another batch was placed on polystyrene foam plates ( $30 \mathrm{~g}$ each) and covered with food wrap and used as the control.

\section{Effect of HVCAP Treatment on the Inoculated ASBS Added without or with $\mathrm{COS}$ at Various Levels}

The HVCAP operating system included dielectricbarrier discharge with a high voltage transformer $(50 \mathrm{~Hz}$,
$230 \mathrm{~V}$ input voltage) and a voltage variac (output voltage controlled within 0-120 kV). All the samples were treated as shown in Figure 1. Firstly, the bags containing slices were filled with working gas, the mixture of argon and oxygen $\left(80 \% \mathrm{Ar} / 20 \% \mathrm{O}_{2}\right.$ and $\left.90 \% \mathrm{Ar} / 10 \% \mathrm{O}_{2}\right)$ using a gas/slice ratio of 3:1 (v/w) using a vacuum-packaging machine Henkovac type 1000 (Tecnovac, Grassobbio (BG), Italy) and heat-sealed. The sealed bags were then treated with HVCAP at $16 \mathrm{kV}$ root mean square for $5 \mathrm{~min}$ ( $2.5 \mathrm{~min}$ for each side of bag) at $28 \pm 2^{\circ} \mathrm{C}$ following the method of Olatunde et al. (2019b). Samples were kept at $4^{\circ} \mathrm{C}$ and analyses were conducted at 0 and $24 \mathrm{~h}$ after HVCAP treatment.

\section{Microbiological Analysis}

Microbiological analysis was done by means of spread plate method as described by Shiekh et al. (2019). Briefly, the sample (10 g) was blended with 90 $\mathrm{mL}$ of saline $(0.85 \%)$ using an M400 Stomacher blender (Seward Limited, Worthington, England). The mixture with appropriate dilutions was inoculated Pseudomonas isolation agar plates and incubated at $25 \circ \mathrm{C}$ for $24 \mathrm{~h}$.

\section{Chemical Analyses}

Total volatile base nitrogen (TVB-N) and trimethylamine (TMA) contents of all samples were examined using the Conway disc method as described by Prabhakar et al. (2019). A sample ( $2 \mathrm{~g}$ ) was added to $8 \mathrm{ml}$ of $4 \%$ trichloroacetic acid $(\mathrm{w} / \mathrm{v})$ and homogenized with a homogenizer (IKA Labortechnik, Malaysia) at a

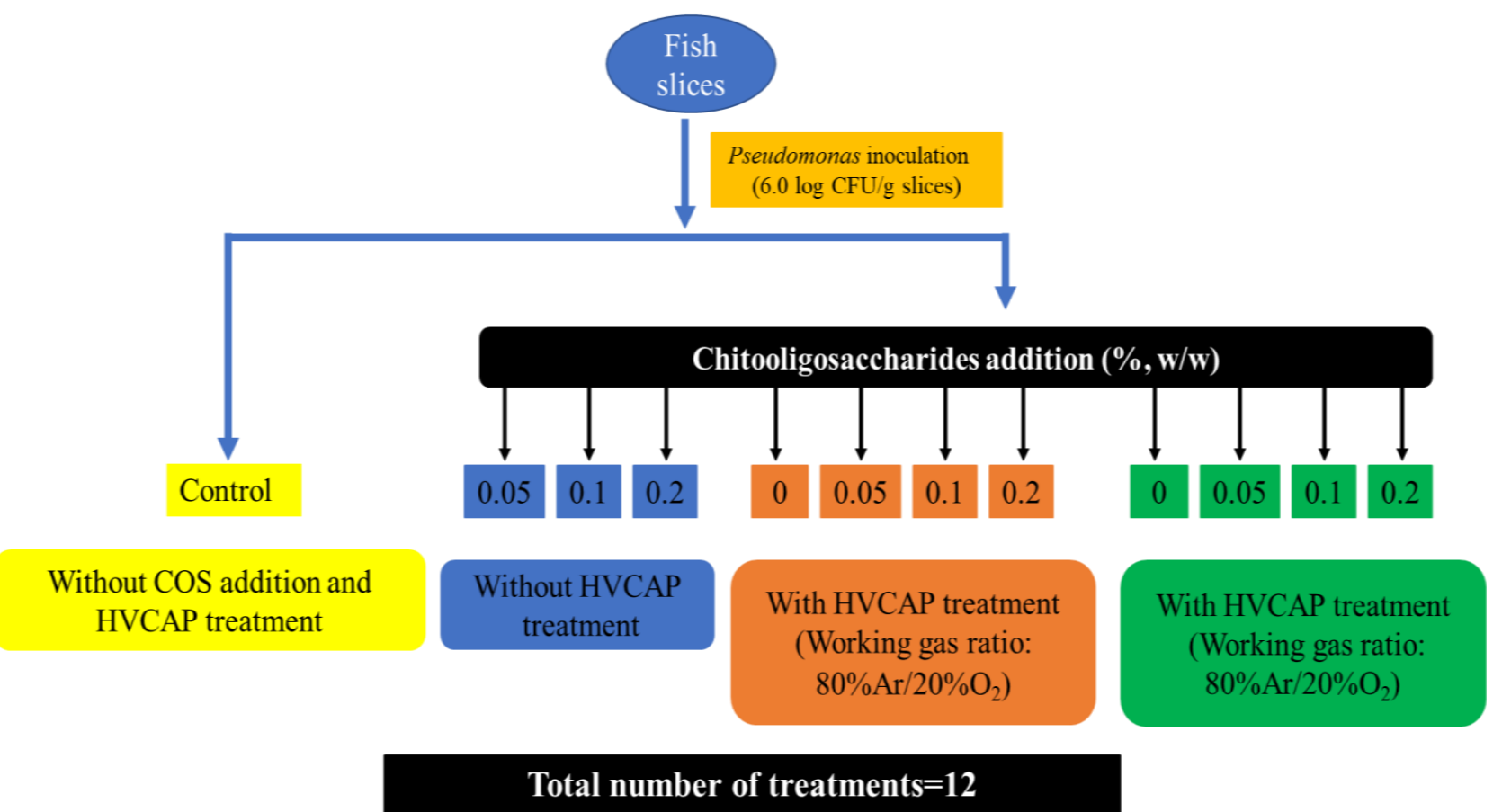

*HVCAP: High Voltage Cold Atmospheric Plasma

Figure 1. Schematic illustration of fish slices without and with chitooligosaccharide addition (COS) and high voltage cold atmospheric plasma (HVCAP) treatment. 
speed of $11,000 \mathrm{rpm}$ for $2 \mathrm{~min}$ and filtered using Whatman filter paper no. 4. The supernatant $(1 \mathrm{ml})$ was placed in the outer ring of the Conway apparatus. The inner ring solution containing $2 \%$ boric acid, $0.1 \%$ bromocresol, and $0.1 \%$ methyl red was then pipetted into the inner ring. To initiate the reaction, $\mathrm{K}_{2} \mathrm{CO}_{3}(1 \mathrm{ml})$ was mixed with sample. The Conway unit was closed and incubated at $37^{\circ} \mathrm{C}$ for $45 \mathrm{~min}$. The inner ring solution was then titrated with $0.02 \mathrm{~N} \mathrm{HCl}$ until the green color turned to pink. Determination of TMA content was carried in the same manner except that $1 \mathrm{ml}$ of $10 \%$ formaldehyde was added to the sample extract to fix ammonia present in the sample prior to the assay. TBA and TMA contents were expressed as $\mathrm{mg} \mathrm{N} / 100 \mathrm{~g}$ sample.

The procedures for determination of peroxide value (PV) and thiobarbituric acid reactive substances (TBARS) were adopted from Arfat et al. (2015). Samples $(0.5 \mathrm{~g})$ were homogenized with $2.5 \mathrm{~mL}$ of TBARS solution (containing $0.0375 \mathrm{~g} / 100 \mathrm{~mL}$ thiobarbituric acid, 15 $\mathrm{g} / 100 \mathrm{~mL}$ trichloroacetic acid and $0.25 \mathrm{~mol} / \mathrm{L} \mathrm{HCl}$ ), followed by boiling for $10 \mathrm{~min}$. The mixture was centrifuged for $15 \mathrm{~min}$ at $8000 \mathrm{xg}$ and absorbance was measured at $532 \mathrm{~nm}$. The TBARS values were expressed as $\mathrm{mg}$ malondialdehyde (MDA)/kg sample.

For PV, the sample $(2 \mathrm{~g})$ was homogenized with 22 $\mathrm{mL}$ of methanol/chloroform (MC) mixture $(1: 2, \mathrm{v} / \mathrm{v})$ at a speed of $15,000 \mathrm{rpm}$ for $1 \mathrm{~min}$. Thereafter, $7 \mathrm{~mL}$ of homogenate was vortexed for $30 \mathrm{sec}$ with $2 \mathrm{~mL}$ of $\mathrm{NaCl}$ $(0.5 \%, \mathrm{w} / \mathrm{v})$ and centrifuged for $3 \mathrm{~min}$ at $3000 \times \mathrm{g}$ at $4{ }^{\circ} \mathrm{C}$. The $50 \mu \mathrm{L}$ of sample was mixed with $2.5 \mathrm{~mL} \mathrm{MC}$ mixture, $50 \mu \mathrm{L}$ of $30 \mathrm{~g} / 100 \mathrm{~g}$ ammonium thiocyanate and $50 \mu \mathrm{L}$ of $20 \mathrm{mmol} / \mathrm{L}$ iron (II) chloride. Then mixtures were vortexed before determination of PV at OD500. The values were denoted as $\mathrm{mg}$ cumene hydroperoxide/ $\mathrm{kg}$ sample

Total carbonyl content (TCC) was determined using 2,4-dinitrophenylhydrazine (DNPH) (Olatunde et al., 2019a). In brief, sample (1 g) was homogenized with 10
$\mathrm{mL}$ of $20 \mathrm{mM}$ Tris buffer containing $0.6 \mathrm{M} \mathrm{NaCl}(\mathrm{pH}$ 6.8) and the obtained solution was treated with 2,4dinitrophenylhydrazine (DNPH) to determine TCC. The content was expressed as $\mu$ mole carbonyl/g protein.

\section{Scanning Electron Microscopy (SEM)}

Impact of selected condition of COS and HVCAP treatment on Pseudomonas was studied using SEM. Pseudomonas suspension (6 $\log \mathrm{CFU} / \mathrm{mL}$ ) without and with $\operatorname{COS}$ at minimum inhibitory concentration $(0.31$ $\mathrm{mg} / \mathrm{mL}$ ) was prepared (Singh et al., 2019a). Additionally, suspension treated with HVCAP using $90 \% \mathrm{Ar} / 10 \% \mathrm{O}_{2}$ as working gases for $5 \mathrm{~min}$ added without and with COS was also prepared. All suspensions were nurtured for 24 $\mathrm{h}$ at $37^{\circ} \mathrm{C}$ and visualized using SEM following the protocol of Olatunde et al. (2019a).

\section{Statistical Analysis}

All experiments were performed in triplicate and data was applied to the one-way analysis of variance (ANOVA). The confidence level $(\alpha)$ was used at $95 \%$. Duncan's multiple range test from SPSS package (SPSS 22 for Windows, SPSS Inc., Chicago, IL, USA) was used for comparison of means. Paired comparison was done using t-test.

\section{Results and Discussion}

Effect of COS and HVCAP under Different Conditions on the Inactivation of Pseudomonas Inoculated on ASBS

The influence of COS at various levels without and with HVCAP treatment using different working gases on the counts of Pseudomonas inoculated on ASBS is shown in Table 1. With addition of COS, the Pseudomonas count $(P C)$ decreased in a dose dependent manner at

Table 1. Effects of COS and HVCAP under different conditions on Pseudomonas count of Asian sea bass slices (ASBS) at 0 and $24 \mathrm{~h}$ of incubation at 4 으

\begin{tabular}{|c|c|c|c|}
\hline \multirow[t]{2}{*}{ HVCAP/working gas } & \multirow{2}{*}{$\begin{array}{c}\text { Cos levels } \\
(\%)\end{array}$} & \multicolumn{2}{|c|}{$\begin{array}{c}\text { Pseudomonas count (PC) } \\
\text { (log CFU/mL) }\end{array}$} \\
\hline & & $\mathrm{Oh}$ & $24 \mathrm{~h}$ \\
\hline \multirow{4}{*}{ No treatment } & $0 *$ & $6.47 \pm 0.08^{\mathrm{aAy}}$ & $6.68 \pm 0.10^{\mathrm{aAx}}$ \\
\hline & 0.05 & $5.30 \pm 0.09^{\mathrm{bBx}}$ & $4.35 \pm 0.07^{b B y}$ \\
\hline & 0.1 & $5.14 \pm 0.13^{\mathrm{cCx}}$ & $4.15 \pm 0.09^{c c y}$ \\
\hline & 0.2 & $5.00 \pm 0.11^{d D x}$ & $4.04 \pm 0.02^{\mathrm{dDy}}$ \\
\hline \multirow{4}{*}{$80 \% \operatorname{Ar} / 20 \% \mathrm{O}_{2}$} & 0 & $3.97 \pm 0.12^{\mathrm{eBx}}$ & $4.02 \pm 0.10^{\mathrm{cBx}}$ \\
\hline & 0.05 & $3.56 \pm 0.06^{f C x}$ & $3.58 \pm 0.10^{c d C x}$ \\
\hline & 0.1 & $3.49 \pm 0.07 \mathrm{gDx}$ & $3.52 \pm 0.07^{d C x}$ \\
\hline & 0.2 & $3.37 \pm 0.11^{\mathrm{hEx}}$ & $3.41 \pm 0.09^{c D x}$ \\
\hline \multirow{4}{*}{$90 \% \mathrm{Ar} / 10 \% \mathrm{O}_{2}$} & 0 & $4.05 \pm 0.14^{\mathrm{eBx}}$ & $4.10 \pm 0.11^{\mathrm{cBx}}$ \\
\hline & 0.05 & $3.57 \pm 0.11^{f C x}$ & $3.61 \pm 0.09 \mathrm{ccx}$ \\
\hline & 0.1 & $3.54 \pm 0.10^{f C x}$ & $3.58 \pm 0.11^{\mathrm{cd} C x}$ \\
\hline & 0.2 & $3.47 \pm 0.09 \mathrm{gDx}$ & $3.50 \pm 0.13^{\mathrm{cdDx}}$ \\
\hline
\end{tabular}

Values are expressed as mean \pm SD $(n=3)$. Different lowercase superscripts $(a, \ldots d, \ldots h)$ in the same column indicate significant differences $(p<0.05)$. Different lowercase superscripts $(x, y)$ in the same row indicate significant differences $(p<0.05)$. Different uppercase superscripts in the same column within the same HVCAP treatment including the control indicated significant difference $(p<0.05)$.

*Control (without HVCAP and COS treatment) 
both 0 and $24 \mathrm{~h}$ of incubation $(\mathrm{p}<0.05)$. PC at different concentrations of COS was in the range of 5-5.14 and 4.04-4.35 $\log \mathrm{CFU} / \mathrm{mL}$ for 0 and $24 \mathrm{~h}$ of incubation, respectively. On the other hand, $\mathrm{PC}$ increased in control samples after $24 \mathrm{~h}$, while the treatment with $\operatorname{COS}$ at different levels significantly decreased PC $(p<0.05)$. Slices incorporated with $\mathrm{COS}$ at different concentrations (0.05, 0.1 and $0.2 \%$ ) showed approximately 1.0-1.5 log reduction in $\mathrm{PC}$ as compared to the control at $0 \mathrm{~h}$ $(p<0.05)$. With increasing concentration of COS to $0.2 \%$, the lowest PC was observed at $0 \mathrm{~h}(\mathrm{p}<0.05)$. This was plausibly associated with antimicrobial activity of COS (Lodhi et al., 2014). Pseudomonas is a Gram negative bacterium in which the cell wall contains only a single layer of peptidoglycan, which makes it more susceptible to antibacterial agents. The positively charged $-\mathrm{NH}_{3}{ }^{+}$ groups of COS might interact with negatively charged compounds of bacteria (Raafat \& Sahl, 2009). This more likely caused the leakage of intracellular substances, resulting in the failure of various intracellular metabolisms of bacterial cells (Lodhi et al., 2014). Additionally, chelation of essential nutrients and metals for microbial growth could be the plausible mechanism for inactivation of microbes by COS (Lodhi et al., 2014). After $24 \mathrm{~h}$ of incubation, more than 2 log reductions in PC was observed for the slices added with COS, as compared to that of control. The higher reduction in PC after $24 \mathrm{~h}$ is plausibly due to the penetration of COS into the cytoplasm of bacterial cell, causing modification of lipids, proteins, RNA, and DNA and leading to the death of microorganisms (Lodhi et al., 2014).

For HVCAP treatment, both working gases $\left(90 \% \mathrm{Ar} / 10 \% \mathrm{O}_{2}\right.$ and $\left.80 \% \mathrm{Ar} / 20 \% \mathrm{O}_{2}\right)$ reduced $\mathrm{PC}$ of the slices, irrespective of COS addition $(p<0.05)$. In the absence of $\mathrm{COS}$, the mixture of $80 \% \mathrm{Ar} / 20 \% \mathrm{O}_{2}$ and $90 \% \mathrm{Ar} / 10 \% \mathrm{O}_{2}$ reduced the $\mathrm{PC}$ by 2.5 and $2.4 \mathrm{log}$ than the control $(p<0.05)$, respectively after the treatment $(0$ h). However, different working gases had no significant impact on the inactivation of bacterial cells. Similar finding was observed by Olatunde et al. (2019a) against various pathogenic and spoilage bacteria enumerated from ASBS stored at 4 으 for 18 days. Generally, when the $\mathrm{O}_{2}$ level was augmented from 10 to $20 \%$, ozone generation was not sufficiently increased to cause significant reduction in microbial population (Olatunde et al., 2019a). Thus, compositional $\mathrm{O}_{2}$ level in working gas had no marked impact on inhibition of Pseudomonas inoculated on slices. The decrease in PC was more likely due to the antimicrobial activity of reactive oxygen species (ROS) and reactive nitrogen species (RNS) generated by HVCAP (Misra et al., 2011). Moreover, the injured cell wall and oxidation of proteins, lipids, and nucleic acids due to HVCAP treatment also could account for its antibacterial activity (Laroussi et al., 2003). Antibacterial properties of ozone in trout species and striped red mullet against various pathogenic and spoilage bacteria were reported by Dehkordi and Zokaie (2010) and Bono and Badalucco (2012), respectively. Slices treated with HVCAP using both working gases showed higher decrease in PC when being treated with COS, particularly at higher levels for both 0 and $24 \mathrm{~h}$ of incubation, ascertained by the higher inactivation rates compared to the use of HVCAP or COS alone $(p<0.05)$. This is more likely due to the increase in penetration of COS into bacterial cells through the pore generated by HVCAP treatment. Olatunde et al. (2019) reported that ROS and RNS generated during HVCAP disappeared after one hour of the treatment. Similar findings were observed by Han et al. (2016) against Escherichia coli and Staphylococcus aureus. Thus, the addition of COS with antimicrobial activity could enhance the shelf-life of slices when active species generated from HVCAP such as ROS, RNS etc. were decomposed. Therefore, a shelf-life study should be performed to assess the antimicrobial activity of the treatments and their influence on the quality attributes of the ASBS.

\section{Effect of COS and HVCAP under Different Conditions on PV and TBARS Values of ASBS}

Effect of COS and HVCAP treatment alone or in combination on PV and TBARS values of ASBS stored for 0 and $24 \mathrm{~h}$ at $4 . \mathrm{C}$ is shown on Table 2 . Slices without COS addition showed higher PV than those subjected to HVCAP, using both working gases at $0 \mathrm{~h}(\mathrm{p}<0.05)$. Lowest PV was noticed for all COS incorporated samples (at $0 \mathrm{~h}$ ) $(p<0.05)$. The alleviation in PV was more probably owing to the antioxidant activity of COS. After $24 \mathrm{~h}$ of incubation, there was an increase in PV of the control (without COS addition and HVCAP) $(p<0.05)$. No significant difference in $\mathrm{PV}$ was detected for slices added with $\operatorname{COS}$ at the levels of 0.05 and $0.1 \% \quad(p>0.05)$. Nevertheless, the slices treated with $\operatorname{COS}$ at $0.2 \%$ showed lower PV, as compared to that found at $0 \mathrm{~h}$ $(p<0.05)$. Asian sea bass is prone to oxidation even stored at lower temperature (Maqsood \& Benjakul, 2010). Decomposition of primary oxidation products to secondary ones can lead to the lower PV (Maqsood \& Benjakul, 2010). Additionally, the increase in PC might cause release of microbial lipase, which could generate free fatty acids by lipid hydrolysis. Free fatty acids are act as prooxidant, which might cause the increase in PV of the control (Singh \& Benjakul, 2020). Lipase from various microbes including Thermomycetes lanuginosus, Candida antarctica and Rhizomucor miehei are reported to hydrolyze lipid from various oils (Karlovec et al., 2012). The decreased PV values at both 0 and $24 \mathrm{~h}$ of slices added with COS, were mainly caused by antioxidative as well as antibacterial activity of COS. Antioxidative activity of $\mathrm{COS}$ was due to $-\mathrm{NH}_{2}$ and $-\mathrm{OH}$ groups present in pyranose ring (Lodhi et al., 2014). Free radicals can be stabilized by the interaction with the free $-\mathrm{NH}_{2}$ groups of COS. Moreover, ammonium groups $\left(\mathrm{NH}_{3}{ }^{+}\right)$generated due to the absorption of hydrogen from solution by $-\mathrm{NH}_{2}$ groups, can work as $\mathrm{H}$-donor to the radicals (Je et al., 2004). Additionally, $-\mathrm{OH}$ group of COS might react with free radicals by the typical $\mathrm{H}$ donation (Xie et al., 2001). 
The slices treated with HVCAP using $80 \% \mathrm{Ar} / 20 \% \mathrm{O}_{2}$ as working gas without COS showed the highest PV, followed by those with HVCAP using $90 \% \mathrm{Ar} / 10 \% \mathrm{O}_{2}$ at both incubation times $(p<0.05)$. However, PV was decreased drastically when slices were treated with HVCAP and COS, especially with increasing COS levels from 0.05 to $0.2 \%$ at both 0 and $24 \mathrm{~h}(\mathrm{p}<0.05)$. Seafoods are rich in polyunsaturated fatty acids and monounsaturated fatty acids, which are easily oxidized by ROS, RNS and light generated during HVCAP treatment (Olatunde et al., 2019a, b). Therefore, COS more likely acted as a radical scavenger and lowered lipid oxidation chain reaction. HVCAP treated slices added without and with COS showed decreased PV after the incubation for $24 \mathrm{~h}(\mathrm{p}<0.05)$. This was more likely due to the decomposition of primary oxidation product such as hydroperoxide to the secondary products (Maqsood \& Benjakul, 2010). Additionally, inhibition of Pseudomonas growth by COS might contribute to the lower peroxide value (PV) after $24 \mathrm{~h}$ of incubation.

TBARS values, representing the secondary oxidation products of lipids, without HVCAP treatment, were decreased when COS was added in a dose dependent manner as compared to the control (without $\cos$ addition) at both incubation times $(p<0.05)$, which confirmed antioxidant activity of COS. When slices treated with HVCAP without the addition of COS, the highest TBARS values were obtained, especially as $80 \% \mathrm{Ar} / 20 \% \mathrm{O}_{2}$ working gas was used, followed by $90 \% \mathrm{Ar} / 10 \% \mathrm{O}_{2}$. Higher rate of $\mathrm{O}_{2}$ could produce higher amounts of active species or radicals, which could induce lipid oxidation more efficiently. Nevertheless, TBARS values were decreased with increasing levels of COS and lower values were obtained in slices added with $0.2 \% \operatorname{COS}$ at both 0 and $24 \mathrm{~h}$. Higher TBARS values were obtained for all the slices at $24 \mathrm{~h}$ as compared to $0 \mathrm{~h}$ $(p<0.05)$. However, no difference was detected in TBARS values for slices added with 0.1 and $0.2 \% \cos$ without
HVCAP treatment ( $p>0.05)$. Higher TBARS values were more possibly due to higher degradation of primary oxidation products to secondary oxidation products generated during HVCAP treatment (Maqsood \& Benjakul, 2010). The increased TBARS values were in agreement with lower PV obtained for most of the treatments after $24 \mathrm{~h}$ of incubation (Table 2). The higher concentration of $\operatorname{cOS}$ might terminate the lipid oxidation by scavenging free radical or inhibition of Pseudomonas growth, resulting in the lower levels of free fatty acids. Therefore, COS showed the potential inhibition towards lipid oxidation of slices caused by both HVCAP treatment and microbial spoilage.

\section{Effect of COS and HVCAP under Different Conditions on Total Carbonyl Content (TCC) of ASBS}

TCC of Pseudomonas inoculated ASBS treated with or without COS and HVCAP alone or in combination at 0 and $24 \mathrm{~h}$ of incubation at $4{ }^{\circ} \mathrm{C}$ is shown in Table 3 . The slices added with COS and without HVCAP treatment showed a decrease in TCC as the concentration of COS was increased up to $0.2 \%(p<0.05)$ indicating protein oxidation of Pseudomonas inoculated slices was impeded. After incubation for $24 \mathrm{~h}$, protein might undergo oxidation to higher extent. Microbial protease, which could lead to the formation of free amino acid, leading to the ease of carbonyl formation (Chanarat et al., 2015). Moreover, 4-hexyl-2 nonenal or malondialdehyde, secondary lipid oxidation products, could attach to the cleaved peptide, thus resulting in the formation of carbonyl in protein (Estévez, 2011). The result was in accordance with the occurrence of lipid oxidation as indicated by increased PV and TBARS values of slices without COS addition (Table 2). Lower TCC values in slices treated with COS (and without HVCAP) compared to control samples could be more probably associated with antibacterial and antioxidant activities

Table 2. Effects of COS and HVCAP under different conditions on peroxide value (PV) and thiobarbuturic acid reactive substance (TBARS) of Asian sea bass slices (ASBS) at 0 and $24 \mathrm{~h}$ of incubation at 4 으

\begin{tabular}{|c|c|c|c|c|c|}
\hline \multirow{2}{*}{ HVCAP/working gas } & \multirow{2}{*}{$\begin{array}{c}\text { COS levels } \\
(\%)\end{array}$} & \multicolumn{2}{|c|}{ PV (mg cumene hydroperoxide equivalent/g sample) } & \multicolumn{2}{|c|}{ TBARS (mg MDA/kg of fish) } \\
\hline & & $\mathrm{Oh}$ & $24 \mathrm{~h}$ & $\mathrm{Oh}$ & $24 \mathrm{~h}$ \\
\hline \multirow{4}{*}{ No treatment } & $0^{*}$ & $0.63 \pm 0.10^{\text {hAEy }}$ & $0.79 \pm 0.05^{\mathrm{gADx}}$ & $1.60 \pm 0.09^{f A E C y}$ & $1.86 \pm 0.18^{\mathrm{eACx}}$ \\
\hline & 0.05 & $0.45 \pm 0.18^{\mathrm{iBx}}$ & $0.45 \pm 0.03^{\mathrm{iBx}}$ & $1.26 \pm 0.03 \mathrm{gBy}$ & $1.34 \pm 0.02^{\mathrm{fBx}}$ \\
\hline & 0.1 & $0.41 \pm 0.11^{\mathrm{iBx}}$ & $0.37 \pm 0.03^{\mathrm{jcx}}$ & $1.14 \pm 0.09^{\mathrm{hCx}}$ & $1.19 \pm 0.09 \mathrm{~g} C \mathrm{x}$ \\
\hline & 0.2 & $0.40 \pm 0.11^{\mathrm{iBx}}$ & $0.34 \pm 0.01^{\mathrm{jCy}}$ & $0.45 \pm 0.05^{\mathrm{jDx}}$ & $0.46 \pm 0.03^{\mathrm{iDx}}$ \\
\hline \multirow{4}{*}{$80 \% \mathrm{Ar} / 20 \% \mathrm{O}_{2}$} & 0 & $6.32 \pm 0.31^{\mathrm{aAx}}$ & $5.87 \pm 0.65^{\mathrm{aAy}}$ & $3.08 \pm 0.12^{\mathrm{aAy}}$ & $4.34 \pm 0.30^{\mathrm{aAx}}$ \\
\hline & 0.05 & $3.95 \pm 0.31^{\mathrm{cBx}}$ & $1.61 \pm 0.14^{\mathrm{cBy}}$ & $2.32 \pm 0.20^{c B y}$ & $2.88 \pm 0.18^{\mathrm{cBx}}$ \\
\hline & 0.1 & $1.70 \pm 0.28^{\mathrm{fCx}}$ & $1.07 \pm 0.15^{\mathrm{ecy}}$ & $1.84 \pm 0.07^{\mathrm{eCy}}$ & $1.95 \pm 0.05^{\mathrm{de} C x}$ \\
\hline & 0.2 & $1.24 \pm 0.27 \mathrm{gDx}$ & $0.55 \pm 0.05^{\mathrm{hAy}}$ & $0.56 \pm 0.07^{\mathrm{iDy}}$ & $0.68 \pm 0.05^{\mathrm{hDx}}$ \\
\hline \multirow{4}{*}{$90 \% \mathrm{Ar} / 10 \% \mathrm{O}_{2}$} & 0 & $4.63 \pm 0.57 \mathrm{bAx}$ & $3.87 \pm 0.19^{\mathrm{bAy}}$ & $2.69 \pm 0.17^{\mathrm{bAy}}$ & $3.04 \pm 0.15^{\mathrm{bAx}}$ \\
\hline & 0.05 & $3.42 \pm 0.21^{\mathrm{dBx}}$ & $1.50 \pm 0.29^{с B y}$ & $1.99 \pm 0.09 \mathrm{dBy}$ & $2.13 \pm 0.48^{\mathrm{dBx}}$ \\
\hline & 0.1 & $2.41 \pm 0.33^{\mathrm{eCx}}$ & $1.38 \pm 0.07^{\mathrm{dCy}}$ & $1.67 \pm 0.08^{f C y}$ & $1.83 \pm 0.04^{\mathrm{eCx}}$ \\
\hline & 0.2 & $1.85 \pm 0.37^{f D x}$ & $0.93 \pm 0.14^{f D y}$ & $0.53 \pm 0.09^{\mathrm{ijDy}}$ & $0.70 \pm 0.11^{\mathrm{hDx}}$ \\
\hline
\end{tabular}

Values are expressed as mean $\pm S D(n=3)$. Different lowercase superscripts $(a, \ldots e, \ldots i)$ in the same column indicate significant differences $(p<0.05)$. Different lowercase superscripts $(x, y)$ within the same parameter tested in the same row indicate significant differences ( $<<0.05)$. Different uppercase superscripts in the same column within the same HVCAP treatment including the control indicated significant difference ( $<<0.05)$. *Control (without HVCAP and COS treatment). 
of COS, resulting in inhibition of Pseudomonas growth and retarded lipid oxidation, respectively.

For HVCAP treated slices, the highest TCC value was observed when $80 \% \mathrm{Ar} / 20 \% \mathrm{O}_{2}$ mixture was used as a working gas in the absence of COS for both 0 and $24 \mathrm{~h}$ of incubation, followed by those treated with $90 \% \mathrm{Ar} / 10 \% \mathrm{O}_{2}(\mathrm{p}<0.05)$. However, with the addition of COS, TCC was decreased in a dose dependent manner for HVCAP treated slices for both working gases $(p<0.05)$. The data was in concomitant with the protein oxidation caused by ROS and RNS generated when HVCAP was implemented. After $24 \mathrm{~h}$ of incubation, TCC was increased in the samples treated with HVCAP using both working gases $(p<0.05)$. This was more likely owing to the increase in protein oxidation caused by ozone and other reactive species (Olatunde et al., 2019b). After 24 $h$, a slight increase in TCC was observed for slices containing 0.05 and $0.1 \%$ COS and treated with $80 \% \mathrm{Ar} / 20 \% \mathrm{O}_{2}$ as a working gas $(\mathrm{p}<0.05)$. Nevertheless, slices added with $0.2 \%$ displayed no difference in TCC after $24 \mathrm{~h}$ of incubation ( $p>0.05$ ). On the contrary, there was no difference in TCC observed in slices treated with HVCAP using $90 \% \mathrm{Ar} / 10 \% \mathrm{O}_{2}$ as a working gas at all COS concentrations after $24 \mathrm{~h}$ of incubation ( $p>0.05)$. This is more probably due to the formation of lower amount of ROS and RNS in slices treated with $90 \% \mathrm{Ar} / 10 \% \mathrm{O}_{2}$, compared to $80 \% \mathrm{Ar} / 20 \% \mathrm{O}_{2}$, in which higher amount of $\mathrm{O}_{2}(20 \%)$ was used. The decrease in TCC was more likely due to the antioxidative ability of COS (Lodhi et al., 2014). COS was able to react with unstable free radicals via amino and hydroxyl groups (Fernandes et al., 2010). Rajapakse et al. (2007) documented that carboxylated COS inhibited membrane protein oxidation via direct scavenging of radicals. Similarly, COS from crab shells ceased protein oxidation via radical scavenging in the living cell (Ngo et al., 2008). During oxidation, side chains of proteins can produce carbonyl groups such as ketones and aldehydes (Chanarat et al., 2015).

Consequently, COS reduced the detrimental effect of HVCAP towards slices by lowering the lipid and protein oxidation. COS in combination with HVCAP treatment could be used to lower the off-flavor generated by oxidation products during the treatment of slices.

\section{Total Volatile Nitrogen Base (TVB-N) Content}

The highest TVB-N content was observed for the control (inoculated with Pseudomonas) without HVCAP treatment and $\operatorname{COS}$ addition at 0 and $24 \mathrm{~h}$ of incubation $(p<0.05) \quad$ (Table 3). For slices inoculated with Pseudomonas without HVCAP treatment (without working gases), TVB-N content was decreased with increasing levels of COS, in which the values were from 9.94 to $7.19 \mathrm{mg} \mathrm{N} / 100 \mathrm{~g}$ sample at $0 \mathrm{~h}(\mathrm{p}<0.05)$. After 24 $h$, TVB-N content was increased in the control without any treatment. This correlated well with the increased PC (Table 1). Pseudomonas has been documented as the major spoilage bacterium in fish or other seafoods (Olatunde et al., 2019b; Singh \& Benjakul, 2020). Similarly, TVB-N content of slices was decreased with HVCAP treatment using both working gases, regardless of $\mathrm{COS}$ addition. However, no significant difference was observed in TVB-N content for slices treated with HVCAP using both working gases in the absence of COS ( $p>0.05$ ). Therefore, the composition of working gases had no significant impact on TVB-N content. The lower TVB-N content in HVCAP treated slices suggested the decrease in de-amination of non-protein nitrogenous compounds or rapid inactivation of bacterial population or both (Olatunde et al., 2019a, b). The acceptable TVB$\mathrm{N}$ limit for fish is $35 \mathrm{mg} \mathrm{N} / 100 \mathrm{~g}$ (EU, 1995). For the slices stored for $24 \mathrm{~h}$, no changes in TVB-N content were

Table 3. Effects of COS and HVCAP under different conditions on total carbonyl content (TCC) and total volatile base nitrogen (TVBN) of Asian sea bass slices (ASBS) at 0 and $24 \mathrm{~h}$ of incubation at 4 으

\begin{tabular}{|c|c|c|c|c|c|}
\hline \multirow{2}{*}{$\begin{array}{l}\text { HVCAP/working } \\
\text { gas }\end{array}$} & \multirow{2}{*}{$\begin{array}{c}\text { Cos levels } \\
(\%)\end{array}$} & \multicolumn{2}{|c|}{$\begin{array}{c}\text { TCC } \\
\text { ( } \mu \text { mole carbonyl/g protein) }\end{array}$} & \multicolumn{2}{|c|}{$\begin{array}{c}\text { TVB-N } \\
\text { (mg nitrogen/100 g sample) }\end{array}$} \\
\hline & & $\mathrm{Oh}$ & $24 \mathrm{~h}$ & $\mathrm{Oh}$ & $24 \mathrm{~h}$ \\
\hline \multirow{4}{*}{ No treatment } & 0* & $0.61 \pm 0.01^{\mathrm{eACy}}$ & $0.83 \pm 0.01^{\mathrm{eABx}}$ & $10.58 \pm 0.50^{\mathrm{aAy}}$ & $16.17 \pm 0.39^{a A x}$ \\
\hline & 0.05 & $0.30 \pm 0.01^{\mathrm{cBx}}$ & $0.31 \pm 0.01^{\mathrm{dBx}}$ & $9.94 \pm 0.19^{\mathrm{bBx}}$ & $9.68 \pm 1.01^{\mathrm{bBx}}$ \\
\hline & 0.1 & $0.27 \pm 0.00^{i C x}$ & $0.28 \pm 0.01^{\mathrm{iCx}}$ & $7.24 \pm 0.18^{\mathrm{ccx}}$ & $7.32 \pm 0.35^{\mathrm{ccx}}$ \\
\hline & 0.2 & $0.14 \pm 0.01^{j \mathrm{Dx}}$ & $0.15 \pm 0.00^{j \mathrm{Dx}}$ & $7.19 \pm 0.29^{c c x}$ & $7.22 \pm 0.38^{\mathrm{ccx}}$ \\
\hline \multirow{4}{*}{$80 \% \operatorname{Ar} / 20 \% \mathrm{O}_{2}$} & 0 & $3.32 \pm 0.03^{a A y}$ & $3.91 \pm 0.00^{\mathrm{aAx}}$ & $6.62 \pm 0.39^{\mathrm{dBx}}$ & $6.79 \pm 0.19 \mathrm{dBx}$ \\
\hline & 0.05 & $1.21 \pm 0.01^{\mathrm{cBy}}$ & $1.36 \pm 0.02^{\mathrm{ccx}}$ & $5.39 \pm 0.17 \mathrm{dec} x$ & $5.46 \pm 0.29^{\mathrm{dec} x}$ \\
\hline & 0.1 & $0.63 \pm 0.02^{\mathrm{eCy}}$ & $0.68 \pm 0.04^{f D x}$ & $5.18 \pm 0.53^{\mathrm{eCx}}$ & $5.25 \pm 0.19^{\mathrm{eCx}}$ \\
\hline & 0.2 & $0.32 \pm 0.01 \mathrm{gDx}$ & $0.33 \pm 0.00^{h E x}$ & $4.69 \pm 0.11^{f D x}$ & $4.83 \pm 0.9^{f D x}$ \\
\hline \multirow{4}{*}{$90 \% \mathrm{Ar} / 10 \% \mathrm{O}_{2}$} & 0 & $2.28 \pm 0.02^{\mathrm{bAy}}$ & $2.81 \pm 0.01^{\mathrm{bAx}}$ & $6.09 \pm 0.51^{\mathrm{dBx}}$ & $6.37 \pm 0.91^{\mathrm{dBx}}$ \\
\hline & 0.05 & $1.02 \pm 0.06^{\mathrm{dBx}}$ & $1.10 \pm 0.02^{\mathrm{dCx}}$ & $5.39 \pm 0.20^{\mathrm{dec} x}$ & $5.53 \pm 0.00^{\mathrm{de} C x}$ \\
\hline & 0.1 & $0.52 \pm 0.00^{f D x}$ & $0.53 \pm 0.01^{g D x}$ & $5.04 \pm 0.19 \mathrm{ecx}$ & $5.12 \pm 0.96^{\mathrm{eCx}}$ \\
\hline & 0.2 & $0.29 \pm 0.00^{\mathrm{hEx}}$ & $0.31 \pm 0.02^{\mathrm{hEx}}$ & $4.97 \pm 0.09^{f D x}$ & $5.00 \pm 0.38^{\mathrm{efCx}}$ \\
\hline
\end{tabular}

Values are expressed as mean \pm SD $(n=3)$. Different lowercase superscripts $(a, \ldots e, \ldots j)$ in the same column indicate significant differences $(p<0.05)$. Different lowercase superscripts $(x, y)$ in the same row within the same parameter tested indicate significant differences $(p<0.05)$. Different uppercase superscripts in the same column within the same HVCAP treatment including the control indicated significant difference ( $<<0.05$ ).

*Control (without HVCAP and COS treatment). 
noticeable ( $p>0.05)$, except for the control, where it was increased to $16.17 \mathrm{mg} \mathrm{N} / 100 \mathrm{~g}(\mathrm{p}<0.05)$. Olatunde et al. (2019b) documented the higher increase in TVB-N content ( $45.43 \mathrm{mg} \mathrm{N} / 100 \mathrm{~g}$ ) of untreated ASBS during 9 days of refrigerated storage than the HVCAP treated slices using $90 \% \mathrm{Ar} / 10 \% \mathrm{O}_{2}$ for $5 \mathrm{~min}$, which had lower TVB-N content. Conversely, slices treated with both HVCAP and COS had the lower TVB-N content, particularly when COS concentration was increased (0.05-0.2\%). The lowest TVB-N content was obtained for slices added with $0.2 \%$ COS in combination with HVCAP using both working gases either at 0 or $24 \mathrm{~h}(\mathrm{p}<0.05)$. This could be owing to the antibacterial properties of both COS, which was synergistically enhanced by HVCAP treatment.

Overall, higher $\mathrm{O}_{2}$ ratio in working gas for HVCAP did not have significant impact on the microbial inactivation, while it enhanced the adverse effects on protein and lipid oxidation. HVCAP at higher oxygen concentration (20\%) caused more oxidation of lipids and proteins as compared to the lower concentrations (10\%). Therefore, $90 \% \mathrm{Ar} / 10 \% \mathrm{O}_{2}$ gas mixture would be selected for working gas in further study.

\section{Scanning Electron Microscopic (SEM) Images of Pseudomonas as Affected by COS and HVCAP Alone or in Combination}

Morphology of Pseudomonas as affected by COS and HVCAP treatment $\left(90 \% \mathrm{Ar} / 10 \% \mathrm{O}_{2}\right)$ alone or in combination is illustrated in Figure 2. Pseudomonas treated without COS and HVCAP showed typical smooth and rod-shaped cells (Figure 2A). However, cells treated with $\mathrm{COS}$ at $0.2 \%$ become deformed, lysed and distorted (Figure 2B, marked as yellow arrows). Some bacterial cell showed a thin layer around the cell (marked with black arrows) for the bacteria culture added with COS, which might be due to the electrostatic interaction of $\mathrm{NH}_{2}$ and $-\mathrm{OH}$ of glucosamine unit of $\mathrm{COS}$ with various biomolecules of cell membrane such proteins, phospholipids etc. (Liu et al., 2004). Additionally, lipopolysaccharides of Gram negative bacterial cell wall can also interact with chitosan or its derivatives, thus negatively affecting membrane integrity and permeability (Davydova et al., 2000; Helander et al., 2001). Several interactions could facilitate the
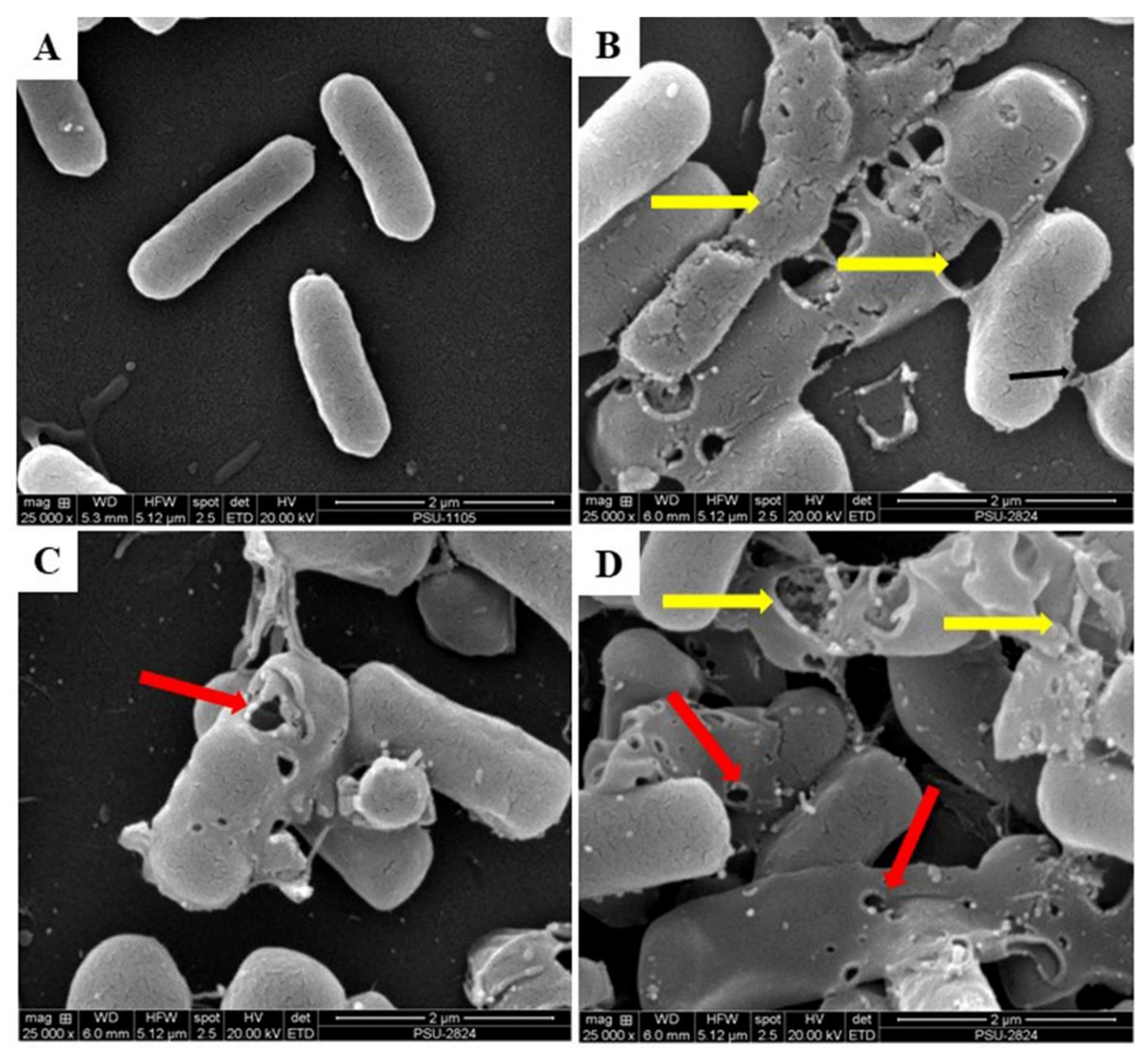

Figure 2. Micrographs of Pseudomonas cell subjected to different treatments. Without treatment (A), with chitooligosaccharide (COS) (B), with high voltage cold atmospheric plasma (HVCAP) and (C), with the combination of COS and HVCAP (D). Cells were treated with HVCAP using $90 \% \mathrm{Ar} / 10 \% \mathrm{O}_{2}$ gas mixture for working gas and COS concentration used was $0.2 \%$. Magnification at 25,000X. Yellow arrows: indicating rupturing of cells; red arrows: indicating poration into cells, black arrow indicated COS binding to cell wall (Figure 2B). 
penetration of COS into bacterial cytoplasm and caused modification of biomolecules such as mRNA, DNA, proteins, etc. This could affect various cellular metabolisms such as protein translation and DNA replication etc., leading to cell death (Lodhi et al., 2014). Bacterial cells treated with HVCAP treatment showed injured and porous cells with a large amount of cell debris (Figure 2C). HVCAP could induce the perforations of surface and alter the inner components of the cell via bombardment induced by various reactive species and plasma particles (Singh \& Benjakul, 2020). Deng et al. (2006) reported slight shrinkage and breakage of the spore membrane, resulting in the leakage of cytoplasm content of Bacillus subtilis spores, when treated with cold atmospheric plasma. Moreover, ROS, UV photons, other charged particles and electric field formed by plasma discharge can cause structural damage of microbial cells (Laroussi et al., 2003). Addition of COS along with HVCAP treatment resulted in the cell with more deformed and distorted structure having higher number of pores (Figure 2D). Pores created by HVCAP treatment augmented the penetration of COS into the cellular cytoplasm. Hence, HVCAP in combination with cOS caused the alternation of morphology such as perforation, leaching of nutrient and modification of various biomolecules of bacterial cells and caused the death of cells.

\section{Conclusions}

cos alone showed potential to inhibit the proliferation of Pseudomonas on ASBS in a dose dependent manner. However, it also enhanced the efficiency of HVCAP in microbial inactivation. HVCAP in combination with $0.2 \%$ COS caused approximately 3 log reduction of Pseudomonas count for both working gases and lowered TVB-N content. However, different ratios of working gases used for HVCAP showed no significant impact on Pseudomonas count. Nevertheless, a high oxygen ratio in working gas resulted in more oxidation of both lipids and proteins of slices. Lipid and protein oxidation were less noticeable in HVCAP treated samples, when COS was added at the level of $0.2 \%$. Therefore, HVCAP treatment $\left(90 \% \mathrm{Ar} / 10 \% \mathrm{O}_{2}\right)$ in the presence of $0.2 \% \operatorname{COS}$ caused death or inhibited the growth of Pseudomonas, as well as lowered lipid and protein oxidation facilitated by HVCAP. In conclusion, HVCAP in combination with COS could be implemented to extend the shelf-life of Asian sea bass in terms of microbial and oxidative quality.

\section{Acknowledgements}

This research was supported by Postdoctoral Fellowship from Prince of Songkla University, Thailand to Dr. Avtar Singh. Prince of Songkla University (Grant No. AGR6302013N) was acknowledged.

\section{References}

AOAC. (2002). Official Methods of Analysis. Association of Official Analytical Chemists. Washington, DC.

Arfat Y.A., Benjakul S., Vongkamjan K., Sumpavapol P., \& Yarnpakdee S. (2015). Shelf-life extension of refrigerated sea bass slices wrapped with fish protein isolate/fish skin gelatin-ZnO nanocomposite film incorporated with basil leaf essential oil. Journal of Food Science and Technology, 52, 6182-6193.

Bono G., \& Badalucco C. (2012). Combining ozone and modified atmosphere packaging (MAP) to maximize shelf-life and quality of striped red mullet (Mullus surmuletus). LWT-Food Science and Technology, 47, 500504.

Branen A. (1978). Interaction of fat oxidation and microbial spoilage in muscle foods. Pages 156-161. Proceedings Annual Reciprocal Meat Conference.

Chanarat S., Benjakul S., \& Xiong Y.L. (2015). Physicochemical changes of myosin and gelling properties of washed tilapia mince as influenced by oxidative stress and microbial transglutaminase. Journal of Food Science and Technology, 52, 3824-3836.

Davydova V., Yermak I., Gorbach V., Krasikova I., \& Solov eva T. (2000). Interaction of bacterial endotoxins with chitosan. Effect of endotoxin structure, chitosan molecular mass, and ionic strength of the solution on the formation of the complex. Biochemistry $\mathrm{C} / \mathrm{C}$ of Biokhimiia, 65, 1082-1090.

Dehkordi B.M., \& Zokaie N. (2010). Extension of fish shelf life by ozone treatment. International Journal of Environmental, Chemical, Ecological, Geological and Geophysical Engineering, 4, 108-110.

Deng X., Shi J., \& Kong M.G. (2006). Physical mechanisms of inactivation of Bacillus subtilis spores using cold atmospheric plasmas. IEEE Transactions on Plasma Science, 34, 1310-1316.

DeWitt C.A.M., \& Oliveira A. (2016). Modified atmosphere systems and shelf life extension of fish and fishery products. Foods, 5, 48.

Estévez M. (2011). Protein carbonyls in meat systems: a review. Meat Science, 89, 259-279.

EU. (1995). Commission Decision 95/149/EC of 8 March 1995 fixing the total volatile basic nitrogen (TVB-N) limit values for certain categories of fishery products and specifying the analysis methods to be used. Official Journal. L, 97, 84-87.

Fernandes J.C., Eaton P., Nascimento H., Gião M.S., Ramos Ó.S., Belo L., Santos-Silva A., Pintado M.E., \& Malcata F.X. (2010). Antioxidant activity of chitooligosaccharides upon two biological systems: erythrocytes and bacteriophages. Carbohydrate Polymers, 79, 1101-1106.

Gavahian M., Chu Y.-H., Mousavi Khaneghah A., Barba F.J., \& Misra N.N. (2018). A critical analysis of the cold plasma induced lipid oxidation in foods. Trends in Food Science and Technology, 77, 32-41.

Gram L., \& Dalgaard P. (2002). Fish spoilage bacteria problems and solutions. Current Opinion in Biotechnology, 13, 262-266.

Han L., Patil S., Boehm D., Milosavljević V., Cullen P., \& Bourke P. (2016). Mechanisms of inactivation by high-voltage atmospheric cold plasma differ for Escherichia coli and Staphylococcus aureus. Applied and Environmental Microbiology, 82, 450-458.

Helander I., Nurmiaho-Lassila E.-L., Ahvenainen R., Rhoades J., \& Roller S. (2001). Chitosan disrupts the barrier properties of the outer membrane of Gram-negative 
bacteria. International Journal of Food Microbiology, 71, 235-244.

Je J.-Y., Park P.-J., \& Kim S.-K. (2004). Free radical scavenging properties of hetero-chitooligosaccharides using an ESR spectroscopy. Food and Chemical Toxicology, 42, 381387.

Kralovec J.A., Zhang S., Zhang W., \& Barrow C.J. (2012). A review of the progress in enzymatic concentration and microencapsulation of omega-3 rich oil from fish and microbial sources. Food Chemistry, 131, 639-644.

Laroussi M., Mendis D.A., \& Rosenberg M. (2003). Plasma interaction with microbes. New Journal of Physics, 5, 4141.

Lodhi G., Kim Y.-S., Hwang J.-W., Kim S.-K., Jeon Y.-J., Je J.-Y., Ahn C.-B., Moon S.-H., Jeon B.-T., \& Park P.-J. (2014). Chitooligosaccharide and its derivatives: preparation and biological applications. BioMed Research International, 2014, 1-14.

Maqsood S., \& Benjakul S. (2010). Synergistic effect of tannic acid and modified atmospheric packaging on the prevention of lipid oxidation and quality losses of refrigerated striped catfish slices. Food Chemistry, 121, 29-38.

Misra N., Tiwari B., Raghavarao K., \& Cullen P. (2011). Nonthermal plasma inactivation of food-borne pathogens. Food Engineering Reviews, 3, 159-170.

Ngo D.-N., Kim M.-M., \& Kim S.-K. (2008). Chitin oligosaccharides inhibit oxidative stress in live cells. Carbohydrate Polymers, 74, 228-234.

Olatunde O.O., Benjakul S., \& Vongkamjan K. (2019a). High voltage cold atmospheric plasma: antibacterial properties and its effect on quality of Asian sea bass slices. Innovative Food Science and Emerging Technologies, 52, 305-312.

Olatunde O. O., Benjakul S., \& Vongkamjan K. (2019b). Combined effects of high voltage cold atmospheric plasma and antioxidants on the qualities and shelf-life of Asian sea bass slices. Innovative Food Science and Emerging Technologies, 54, 113-122.

Pankaj S.K., Wan Z., Colonna W., \& Keener K.M. (2017). Effect of high voltage atmospheric cold plasma on white grape juice quality. Journal of the Science of Food and Agriculture, 97, 4016-4021.

Prabhakar P.K., Srivastav P.P., \& Pathak S.S. (2019). Kinetics of total volatile basic nitrogen and trimethylamine formation in stored rohu (Labeo rohita) fish. Journal of Aquatic Food Product Technology, 28, 452-464.

Raafat D., \& Sahl H.-G. (2009). Chitosan and its antimicrobial potential--a critical literature survey. Microbial Biotechnology, 2, 186-201.

Rajapakse N., Kim M.-M., Mendis E., \& Kim S.-K. (2007). Inhibition of free radical-mediated oxidation of cellular biomolecules by carboxylated chitooligosaccharides. Bioorganic and Medicinal Chemistry, 15, 997-1003.

Rothrock M.J., Zhuang H., Lawrence K.C., Bowker B.C., Gamble G.R., \& Hiett K.L. (2017). In-package inactivation of pathogenic and spoilage bacteria associated with poultry using dielectric barrier discharge-cold plasma treatments. Current Microbiology, 74, 149-158.

Sae-leaw T., \& Benjakul S. (2017). Lipids from visceral depot fat of Asian seabass (Lates calcarifer): Compositions and storage stability as affected by extraction methods. European Journal of Lipid Science and Technology, 119, 1700198.

Shiekh K.A., Benjakul S., \& Sae-leaw T. (2019). Effect of Chamuang (Garcinia cowaRoxb.) leaf extract on inhibition of melanosis and quality changes of Pacific white shrimp during refrigerated storage. Food Chemistry, 270, 554-561.

Singh A., \& Benjakul S. (2020). The combined effect of squid pen chitooligosaccharides and high voltage cold atmospheric plasma on the shelf-life extension of Asian sea bass slices stored at $4^{\circ} \mathrm{C}$. Innovative Food Science and Emerging Technologies, 102339.

Singh A., Benjakul S., \& Kishimura H. (2017). Characteristics and functional properties of ovary from squid Loligo Formosana. Journal of Aquatic Food Product Technology, 26, 1083-1092.

Singh A., Benjakul S., \& Prodpran T. (2019a). Chitooligosaccharides from squid pen prepared using different enzymes: characteristics and the effect on quality of surimi gel during refrigerated storage. Food Production, Processing and Nutrition, 1, 1-10. 10.1186/s43014-019-0005-4/tables/1.

Singh A., Benjakul S., \& Prodpran T. (2019b). Ultrasoundassisted extraction of chitosan from squid pen: molecular characterization and fat binding capacity. Journal of Food Science, 84, 224-234.

Singh A., Mittal A., \& Benjakul S. (2020). Full utilization of squid meat and its processing by-products: revisit. Food Reviews International, 1-25, 10.1080/87559129.87552020.81734611.

Smet C., Baka M., Dickenson A., Walsh J.L., Valdramidis V.P., \& Van Impe J.F. (2018). Antimicrobial efficacy of cold atmospheric plasma for different intrinsic and extrinsic parameters. Plasma Processes and Polymers, 15, 1700048.

Spanu C., Scarano C., Ibba M., Pala C., Spanu V., \& De Santis E.P.L. (2014). Microbiological challenge testing for Listeria monocytogenes in ready-to-eat food: a practical approach. Italian Journal of Food Safety, 3.

Xie W., Xu P., \& Liu Q. (2001). Antioxidant activity of watersoluble chitosan derivatives. Bioorganic and Medicinal Chemistry Letters, 11, 1699-1701. 